\title{
Environmental Correlates of Bronchial Asthma in Children in a Slum of Meerut - A Cross-Sectional Study
}

\author{
George CE ${ }^{1}$, Chopra $\mathrm{H}^{2}$, Garg $\mathrm{SK}^{3}$, Bano $\mathrm{T}^{4}, \mathrm{Jain}^{5}$, Kumar $\mathrm{A}^{6}$
}

${ }^{1}$ Dr. Carolin Elizabeth George, M.D., Consultant, Community Health Department, Bangalore Baptist Hospital, Hebbal, Bellary Road, Bangalore, Karnataka, India, ${ }^{2}$ Dr. H Chopra M.D., D.C.H., Professor, Department of Community Medicine, ${ }^{3}$ Dr. S. K. Garg, M.D., F.I.P.H.A., Professor, ${ }^{4}$ Dr. Tanveer Bano MD, Associate Professor, ${ }^{5}$ Dr. Seema Jain, MD, Assistant Professor, ${ }^{6}$ Dr. Arun Kumar M.D., Assistant Professor. All are affiliated with Department of Community Medicine, L.L.R.M. Medical College, Meerut, UP, India.

Address for correspondence: Dr Carolin Elizabeth George, Email: carolinelizabethj@gmail.com

\begin{abstract}
Introduction: In India, an estimated 57,000 deaths were attributed to Asthma in 2004 \& it was seen as one of the leading cause of morbidity and mortality (WHO 2004). The range of prevalence of Bronchial asthma in children in India varied from $2 \%$ to $20 \%$. So far, no community based studies have been conducted in Western Uttar Pradesh to find out the prevalence of bronchial asthma in children. The present study is an effort in that direction. Objective: To determine the prevalence of bronchial asthma among children of 5 - 15 years and its environmental determinants. Methods: A cross sectional community based study was conducted by interviewing the parents of randomly selected children in the age group of 5- 15 years using International Study on Allergy And Asthma In Childhood (ISAAC) Questionnaire. Assuming the prevalence of bronchial asthma to be $10 \%$ at $95 \%$ confidence interval and allowing a relative precision of $20 \%$ for the estimate and expecting a non response rate of $5 \%$, the sample size was calculated as 907 . The observations thus obtained were tabulated and analysed using relevant statistical methods. Results: A total of 880 children of 5- 15 yrs participated in the study showing a response rate of $97.02 \%$. The prevalence of asthma was found to be $9.3 \%$. The prevalence of asthma was found to be associated with inadequate ventilation $(\mathrm{OR}=2.71)$ and presence of pets $(\mathrm{OR}=2.70)$

Conclusion: The prevalence of asthma was found to be $9.3 \%$ and it warrants a national program to reduce the morbidity in children.
\end{abstract}

Key words: Bronchial Asthma; Children; Environment; ISAAC Questionnaire

\section{Introduction}

According to World Health Organisation (WHO) estimates, 300 million people suffer from Asthma, 255, 000 people died of asthma in 2005 and over $80 \%$ of asthma deaths are reported from low and lower-middle income countries [1]. Asthma creates a substantial burden on individuals and families as it is more often under-diagnosed and under-treated [2].

Paediatric asthma is a serious global health problem. Asthma can considerably impair the child's social interaction and academic achievement. An estimated 1.9 disability adjusted life yr (DALYs) are lost every year due to asthma per thousand children under $15 \mathrm{yr}$ of age in India [3]. The increase in the prevalence of asthma in

Manuscript received: $24^{\text {th }}$ July 2014

Reviewed: $07^{\text {th }}$ Aug 2014

Author Corrected: $24^{\text {th }}$ Aug 2014

Accepted for Publication: $22^{\text {nd }}$ Sep 2014 children may have serious implications for adults as $40 \%$ of children with infrequent trivial wheeze and $70-90 \%$ of those with more troublesome asthma continue to have symptoms in mid-adult life [4]. Environmental tobacco smoke and mould growth are the indoor factors most consistently associated with respiratory morbidity [5].

The prevalence of asthma varies in different parts of India. The southern states show a higher prevalence $(5 \%$ $-10.3 \%$ ) [6-9] compared to northern states $(0.2 \%$ - $4 \%)$ [3, $10,11]$ and an overall of $0.89 \%$ reported by NFHS 3 data [12]. However Singh et al (2004) conducted a study in Punjab among children of $5-17$ years old which reported an urban prevalence of $11.92 \%$ and a rural prevalence of 13.72 with a weighted average of $12.76 \%$ [13]. Chronic symptoms are a key aspect of asthma. Intermittent dry coughing and/or expiratory wheezing are the most 
common chronic symptoms of asthma. Older children and adults will report associated shortness of breath and chest tightness; younger children are more likely to report intermittent, non focal chest "pain." Respiratory symptoms are characteristically worse at night, especially during prolonged exacerbations triggered by respiratory infections or inhalant allergens. Other asthma symptoms in children can be subtle and include decreased physical activity, general fatigue (possibly due to sleep disturbance), and difficulty keeping up with peers in physical activities.

Childhood bronchial asthma has multifactorial causation. Geographical location, environmental, racial as well as factors related to behaviours and lifestyles are associated with the disease. Asthma is one of the most important chronic diseases of childhood, causing substantial morbidity. Increase in the rates of hospital admission and primary care contacts for asthma in childhood has led to concern regarding prevalence or severity of increasing wheezing illness in children. There is paucity of studies in India regarding asthma in children; moreover there are no studies in Uttar Pradesh regarding the treatment modalities adopted by the community. Keeping all the above facts in view, a need was felt to assess the prevalence of bronchial asthma in children to find out prevalence \& determinants of bronchial asthma among children of 5 to 15 years.

\section{Material and Methods}

The present cross sectional community based study was conducted in the slum population registered at the urban health centre Suraj Kund, which is the field practice area of Department of Community Medicine LLRM Medical College Meerut. Assuming the prevalence of bronchial asthma to be $10 \%$ at $95 \%$ confidence interval and allowing a relative precision of $20 \%$ for the estimate, the sample size was calculated as 864 .

The final sample size of 907 was arrived by expecting a non response rate of $5 \%$. Children were selected by systematic random sampling method. Information was collected by interviewing parents along with their child using International Study On Allergy And Asthma In Childhood (ISAAC) Questionnaire after obtaining informed consent from the mothers [14].

The data thus collected, was first coded and then transferred to a master chart on Microsoft Excel, from which distribution as well as association tables were prepared, analyzed and statistically evaluated by SPSS version 15.0. The findings were described in terms of proportions and their $95 \%$ confidence intervals. Chi square tests of significance were carried out to test the differences between proportions. Significance was reported at 5\% level. To determine the independent effect of various factors on bronchial asthma, multiple logistic regression analysis was performed and their significance was estimated in terms of adjusted odds ratio and its $95 \%$ confidence interval. The study is approved by the institutional review board of LLRM Medical college.

\section{Results}

During this study, all the required information could be collected for 880 children yielding a response rate of 97\%. The baseline characteristics were as follows: most of the children were in the 5-9 yr age group (48.2\%) with birth order $1(35.3 \%)$.

The proportion of boys was slightly higher than girls (53.6\% Vs 46.4\%). Majority were Hindus (99.3\%) and most belonged to families with low socio-economic class $(50.1 \%)$ with a high literacy rate among parents (father $77.1 \%$, mother $74.9 \%$ ).

The overall prevalence of bronchial asthma was found to be $9.3 \%$ (95\% C.I. $7.4-11.2)$ among children aged 5-15 yr. Boys had a higher prevalence of asthma (12.5\%) compared to girls $(5.6 \%)$ and the male to female ratio for prevalence was found to be 2.6:1. $\left(\chi^{2}=12.2\right.$, df $=1, \mathrm{p}<$ 0.001).

Table 1: Triggers for an asthmatic episode- Multiple response table

\begin{tabular}{|c|c|}
\hline Trigger & $\begin{array}{c}\text { Number of children } \\
\text { n (\%) }\end{array}$ \\
\hline Respiratory Tract Infection & $73(89.0)$ \\
\hline Smoke & $51(62.2)$ \\
\hline Cold weather & $46(56.1)$ \\
\hline Dust exposure & $32(39.0)$ \\
\hline Exercise & $24(29.3)$ \\
\hline Pollen & $21(25.6)$ \\
\hline Crying/ Hyperventillation & $13(15.9)$ \\
\hline Perfume & $8(9.8)$ \\
\hline Food & $7(8.5)$ \\
\hline Mosquito Repellent & $13(7.3)$ \\
\hline \multicolumn{2}{|c|}{ Base $=82$} \\
\hline
\end{tabular}

The various triggers for an asthmatic attack are described in table 1. Respiratory tract infection was the most common precipitating factor in $89 \%$ of the children. Certain foods acted as triggers in $8.5 \%$ of children. Peanuts, egg, milk, ice cream and refrigerated food were the food items which precipitated asthmatic attack in those children. In $15.9 \%$ of children crying, hyper ventilation or extreme emotional expression resulted in asthmatic attack.

Available online at: www.ijmrr.in 470 | P a g e 
Table 2: Environmental factors associated with the prevalence of asthma

\begin{tabular}{|c|c|c|c|c|c|c|c|c|}
\hline \multicolumn{2}{|c|}{ Parameter } & \multicolumn{2}{|c|}{$\begin{array}{c}\text { Total number } \\
\text { of children }\end{array}$} & \multicolumn{2}{|c|}{$\begin{array}{c}\text { Children with } \\
\text { asthma }\end{array}$} & \multirow{2}{*}{$\begin{array}{c}95 \% \\
\text { confidence } \\
\text { interval }\end{array}$} & \multirow[t]{2}{*}{$\chi^{2}$} & \multirow[t]{2}{*}{ p value } \\
\hline & & No. & $\%$ & No. & $\%$ & & & \\
\hline \multirow{2}{*}{ Ventilation } & Adequate & 507 & 57.6 & 23 & 4.5 & $2.7-6.3$ & \multirow{2}{*}{32.366} & \multirow{2}{*}{$<0.001$} \\
\hline & Inadequate & 373 & 42.4 & 59 & 15.8 & $12.1-19.5$ & & \\
\hline \multirow{2}{*}{ Lighting } & Adequate & 531 & 60.3 & 43 & 8.1 & $5.8-10.4$ & \multirow{2}{*}{2.359} & \multirow{2}{*}{$>0.05$} \\
\hline & Inadequate & 349 & 39.7 & 39 & 11.2 & $7.9-14.5$ & & \\
\hline \multirow{2}{*}{ Overcrowding } & Present & 390 & 44.3 & 60 & 15.4 & $11.8-19$ & \multirow{2}{*}{30.505} & \multirow{2}{*}{$<0.001$} \\
\hline & Absent & 490 & 55.7 & 22 & 4.5 & $2.7-6.3$ & & \\
\hline \multirow{2}{*}{ Dampness } & Present & 249 & 28.2 & 32 & 12.9 & $8.7-17$ & \multirow{2}{*}{5.13} & \multirow{2}{*}{$<\mathbf{0 . 0 3}$} \\
\hline & Absent & 631 & 71.8 & 50 & 7.9 & $5.8-10$ & & \\
\hline \multirow{2}{*}{ Fuel used } & $\begin{array}{c}\text { Non smoke } \\
\text { producing }\end{array}$ & 463 & 52.6 & 37 & 8.0 & $5.5-10.5$ & \multirow{2}{*}{2.036} & \multirow[b]{2}{*}{$>0.1$} \\
\hline & $\begin{array}{c}\text { smoke } \\
\text { producing }\end{array}$ & 417 & 47.4 & 45 & 10.8 & $7.8-13.8$ & & \\
\hline \multirow{2}{*}{ Fungus } & Present & 141 & 16 & 20 & 14.2 & $8.4-19.9$ & \multirow{2}{*}{4.705} & \multirow{2}{*}{$<\mathbf{0 . 0 3}$} \\
\hline & Absent & 739 & 84.0 & 62 & 8.4 & $6.4-10.4$ & & \\
\hline \multirow{2}{*}{ Cockroaches } & Present & 666 & 75.7 & 65 & 9.8 & $7.5-12$ & \multirow{2}{*}{0.632} & \multirow{2}{*}{$>0.4$} \\
\hline & Absent & 214 & 24.3 & 17 & 7.9 & $4.3-11.6$ & & \\
\hline \multirow{2}{*}{ Pets } & Present & 148 & 16.8 & 28 & 18.9 & $12.6-25.2$ & \multirow{2}{*}{19.408} & \multirow{2}{*}{$<0.001$} \\
\hline & Absent & 732 & 83.2 & 54 & 7.4 & $5.5-9.3$ & & \\
\hline \multirow{2}{*}{$\begin{array}{c}\text { Family history } \\
\text { of smoking }\end{array}$} & Present & 135 & 15.3 & 22 & 16.3 & $10.1-22.5$ & \multirow{2}{*}{9.19} & \multirow{2}{*}{$<0.003$} \\
\hline & Absent & 745 & 84.7 & 60 & 8.1 & $6.1-10$ & & \\
\hline
\end{tabular}

Children living in ill ventilated, damp houses with the presence of fungus had more chance of developing asthma as shown in the table 2. The prevalence of asthma in children belonging to pucca and semi pucca houses was $9.2 \%$ and $9.8 \%$ respectively which was not statistically significant. $\left(\chi^{2}=0.039, \mathrm{df}=1 ; \mathrm{p}>0.8\right)$. No association was found between prevalence of asthma and presence of separate kitchen $\left(\chi^{2}=0.258 ; \mathrm{df}=1 ; \mathrm{p}>0.6\right)$. None of the houses had separate smoke outlet. The prevalence of asthma was same $(9.3 \%)$ in children living in houses with indoor plants and without indoor plants.

Multivariate analysis revealed that presence of pets $(\mathrm{OR}=2.70)$ and inadequate ventilation $(\mathrm{OR}=2.71)$ were independently associated with bronchial asthma in children of school going age. [Table 3]

\section{Discussion}

In the present study, the overall prevalence of bronchial asthma among children of school going age group was found to be 9.3\%. The findings of the study were consistent with Jain et al, narayan et al, Singh et al, Parmesh et al \& Chhabra et al $10.3 \%, 8.4 \%, 11.9 \%, 11.2 \% \& 11.9 \%$ respectively $[3,11,13,16,19]$.

However, the prevalence was lesser than that reported by Chhabra et al (1998) and Chakravarthy et al (2002) which were $15.7 \%$ and $18 \%$ respectively. Vishwanathan et al (1966) Multicentric (ISAAC) steering committee (1998) Ravindran et al (2002), Singh et al (2002) National Family Health Survey (NFHS - 3; 2005-2006) and Sharma and Banga (2007) reported a lower prevalence of $0.2 \%, 4.5 \%, 5.2 \% 2.6 \% 0.89 \%$ and $0.3 \%$ respectively $[6,12,14,15]$. 
Table 3: Environmental correlates of asthma - Multiple logistic regression analysis

\begin{tabular}{|c|c|c|c|c|c|c|c|}
\hline \multicolumn{2}{|l|}{ Parameter } & \multirow[t]{2}{*}{$\begin{array}{l}\text { Wald } \\
\text { statistics }\end{array}$} & \multirow[t]{2}{*}{ OR } & \multirow[t]{2}{*}{$\begin{array}{c}\text { Adjusted } \\
\text { OR } \\
\end{array}$} & \multicolumn{2}{|c|}{$\begin{array}{l}95 \% \text { confidence } \\
\text { interval }\end{array}$} & \multirow[t]{2}{*}{ P Value } \\
\hline Ventilation & Adequate $^{\mathrm{R}}$ & & & & & & \\
\hline & Inadequate & 5.159 & 997 & 2.711 & 1.147 & 6.410 & $.023 *$ \\
\hline \multirow{2}{*}{ Overcrowding } & Absent $^{R}$ & & & & & & \\
\hline & Present & 2.489 & .691 & 1.997 & .846 & 4.714 & .115 \\
\hline \multirow[b]{2}{*}{ Dampness } & Absent $^{\mathrm{R}}$ & & & & & & \\
\hline & Present & 3.440 & .642 & .526 & .267 & 1.037 & .064 \\
\hline \multirow[b]{2}{*}{ Fungus } & Absent $^{\mathrm{R}}$ & & & & & & \\
\hline & Present & .006 & .028 & .972 & .473 & 2.001 & .939 \\
\hline \multirow[b]{2}{*}{ Pets } & Absent $^{\mathrm{R}}$ & & & & & & \\
\hline & Present & 13.496 & .993 & 2.701 & 1.590 & 4.588 & $.000 *$ \\
\hline \multirow{2}{*}{$\begin{array}{c}\text { Family history of } \\
\text { smoking }\end{array}$} & Absent $^{R}$ & & & & & & \\
\hline & Present & 3.067 & .508 & 1.663 & .941 & 2.937 & .080 \\
\hline
\end{tabular}

R- Reference category * Statistically significant

The present study observed that respiratory tract infection was the most common precipitating factor in $89 \%$ of children which was higher than $40.0 \%$ and $24.0 \%$ as reported by Paramesh [16] and Joshi et al [17] lesser than $94.7 \%$ as reported by Jain et al [3] .

Prevalence of asthma was significantly higher (15.8\%) in children living in houses with inadequate ventilation as compared to those who were living in houses with adequate ventilation (4.5\%). This finding was also supported by Pokharel et al [18] who observed a strong association between inadequate ventilation and asthma. However, the findings were in contrast with Jain et al [3] who could not find any association between inadequate ventilation and the prevalence of asthma.

In the current study, the prevalence of bronchial asthma was not significantly associated with the type of fuel used for cooking purposes. Similarly, Chhabra et al [19], Singh et al [20] and Jain et al [3] found no significant association between the prevalence of wheeze and asthma with the type of domestic fuel used in kitchen. The present study observed that the prevalence of asthma was significantly higher $(18.9 \%)$ in families with pets than with no pets $(7.4 \%)$ which is similar to studies by Zheng et al [21] and Pokharel et al [22] However Singh et al [20], Paramesh [16] and Jain et al [3] found no association between pets and asthma.

\section{Conclusion}

The present findings highlight that there is a high prevalence of bronchial asthma among children. Most of the research in asthma in India is regionalized or localized and largely uses hospital based data which cannot be easily generalized to the entire Indian population. Therefore, to measure the extent of the problem in the entire population, there is a need for reliable population-based multi-centric epidemiological studies.

Asthmatic children who are sensitized to indoor allergens in particular can experience greater asthma severity due to year-round exposure and can benefit from measures to minimize allergen exposure in the home. They should be educated about the possible triggers and measures should be taken to minimize the exposures. Efforts should be taken to modify the physical and biological environment to reduce the airway morbidity.

\section{Funding: Nil \\ Conflict of interest: Nil \\ Permission from IRB: Yes}

\section{References}

1. Braman SS. The Global Burden of Asthma. Chest 2006 Jul; 130;4S-12S.

2. Rabe KF, Vermeire PA, Soriano JB, Maier WC. Clinical management of asthma in 1999: the Asthma Insights and Reality in Europe (AIRE) study. Eur Respir J. 2000 Nov; 16(5):802-807.

3. Jain A, Vinod Bhat H, Acharya D. Prevalence of Bronchial Asthma in Rural Indian Children: A Cross 
Sectional Study from South India. Indian J Pediatr. 2010 Jan; 77 (1) : 31-35

4. Juniper EF, Wsniewski ME, Cox FM, Emmet AH, Neilson KE, O'Byrne PM. Relationship between psychosocial problem and measures of clinical status in asthma: a factor analysis. Eur Repir J. 2004 Feb; 23(2):287- 291

5. Strachan DP. The role of environmental factors in asthma. Br Med Bull. 2000;56(4):865-82

6. Vishwanathan R, Prasad M, Thakur AK, Sinha SP, Prakash N, Mody RK, et al. Epidemiology of asthma in an urban population. A random morbidity survey. J Indian Med Assoc. 1966 May;46(9):480-3.

7. Gupta D, Aggarwal AN, Kumar R, Jindal SK. Prevalence of bronchial Asthma and association with environmental tobacco smoke exposure in adolescent school children in Chandigarh, North India. J Asthma. 2001 Sep;38(6):501-7.

8. Awasthi S, Kalra E, Roy S, Awasthi S. Prevalence and risk factors of asthma and wheeze in school-going children in Lucknow, North India. Indian Pediatr 2004 Dec;41(12):1205-10.

9. Singh D, Sobti PC, Arora V, Soni RK. Epidemiologicalal study of asthma in rural children. Indian J Community Med 2002;27:167-70.

10. Chakravarthy S, Singh RB, Swaminathan S, Venkatesan P. Prevalence of bronchial asthma in urban and rural children in Tamil Nadu, India. Natl Med J India. 2002 Sep-Oct;15(5):260-3

11. Narayana PP, Prasanna MP, Narahari SR, Guruprasad AM. Prevalence of asthma in school children in rural India. Ann Thorac Med. 2010 Apr;5(2):118-9.

12. Morbidity and Health Care International Institute for Population Sciences (IIPS) and Macro International;
National Family Health Survey (NFHS-3), 2005-06: India: Vol. 1. Mumbai: IIPS; 2007. p. 423.

13. Singh M, Singh SP, Singh K, Bhatia AS, Kajal NC, Aggarwal D, et al. Prevalence of Bronchial Asthma among school children in urban and rural areas. Chest 2004; $126: 762$ S.

14. Worldwide variations in the prevalence of Asthma symptoms :the International study of Asthma and allergies in childhood (ISAAC).. Euro Respir J 1998 Aug;12(2):315-35

15. Agrawal S. Asthma in India.[online] Available from: sancd.org/uploads/pdf/Asthma_factsheet.pdf [ accessed on $11 / 1 / 2012]$

16. Paramesh H. Epidemiology of Bronchial Asthma in India. Indian J Pediatr 2002 Apr;69(4):309- 12.

17. Joshi P, Shaw A, Kakakios A, Isaacs D. Interferongamma levels in nasopharyngeal secretions of infants with respiratory syncytial virus and other respiratory viral infections. Clin Exp Immunol 2003 Jan;131(1):143-7.

18. Pokharel PK, Kabra SK, Kapoor SK, Pandey RM. Risk factors associated with bronchial asthma in school going children of rural Haryana. Indian J Pediatr 2001 Feb; 68(2):103-106

19. Chhabra SK, Gupta CK, Chhabra P, Rajpal S. Risk factors for development of bronchial asthma in children in Delhi. Ann Allergy Asthma Immunol 1999 Nov;83(5):385-90.

20. Singh D, Sobti PC, Arora V, Soni RK. Epidemiologicalal study of asthma in rural children. Indian J Community Med 2002 Oct-Dec;27(4):167-70.

21. Zheng T, Niu S, Lu B, Fan X, Sun F, Wang J, et al.Childhood Asthma in Beijing, China: A Populationbased Case-Control Study.Am J Epidemiol 2002 Nov;156(10):977-983

\section{How to cite this article?}

George CE, Chopra H, Garg SK, Bano T, Jain S, Kumar A. Environmental Correlates of Bronchial Asthma in Children in a Slum of Meerut - A Cross-Sectional Study. Int J Med Res Rev 2014;2(5):469- 473. doi:10.17511/ijmrr.2014.i05.11 